\title{
An Experimental Research of Natural Circulation Heat Transfer for PRHR Heat Exchanger in AP1000
}

\author{
Minghui Duan ${ }^{1}$, Yuzhou Chen ${ }^{1}$, Yvfeng $\mathrm{Lv}^{1}$, Weiqing $\mathrm{Li}^{1}$, Keming Bi ${ }^{1}$, Wei Wang ${ }^{1}$, Kaiwen Du ${ }^{1}$ and $\mathrm{Han} \mathrm{Wang}^{2}$ \\ 1. China Institute of Atomic Energy, P.O. Box 275(59), Beijing 102413, China \\ 2. State Nuclear Power Technology Research \& Development Centre, Beijing 102209, China
}

Received: May 20, 2016 / Accepted: June 02, 2016 / Published: September 30, 2016.

\begin{abstract}
The heat transfer characteristics of the PRHR (passive residual heat removal) HX (heat exchanger) are very important to reactor design and safety assessment of AP1000. The purpose of the present experiment was to obtain the natural circulation data in HX to research the heat transfer behavior. The PRHR HX was simulated by three C-type tubes with prototype sizes immerged in a cooling tank. Separate-effect tests of natural circulation in HX tubes have been performed within wide conditions which could cover the operation conditions in AP1000. The experiment provided lots of important data to indicate heat transfer phenomena of PRHR HX. The test conditions were calculated by RELAP5/MOD3.3. The calculation results agreed well with the experiment. RELAP5 could be applied with proper correlations to analyze the heat transfer in PRHR HX under the test conditions.
\end{abstract}

Key words: PRHR HX, natural circulation, separate-effect tests, AP1000.

\section{Nomenclature}

$\begin{array}{ll}N u_{D B} & \text { Nusselt number } \\ h_{D B} & \text { Convective heat transfer coefficient, } \mathrm{W} / \mathrm{m}^{2} \cdot \mathrm{K} \\ D_{i} & \text { Inner-tube diameter, } \mathrm{m} \\ k_{i} & \text { Thermal conductivity, } \mathrm{W} / \mathrm{m} \cdot \mathrm{K} \\ \mathrm{Re} & \text { Reynolds number } \\ \mathrm{Pr} & \text { Prandtl number } \\ L & \text { Tube length, } \mathrm{m} \\ h_{\text {Nusselt }} & \text { Heat transfer coefficient, } \mathrm{W} / \mathrm{m}^{2} \cdot \mathrm{K} \\ \delta & \text { Film thickness, } \mathrm{m} \\ h_{S h a h} & \text { Heat transfer coefficient, } \mathrm{W} / \mathrm{m}^{2} \cdot \mathrm{K} \\ \mathrm{X} & \text { Static vapor quality } \\ P_{r e d} & \text { Reduced bulk pressure } \\ h_{s f} & \text { Superficial heat transfer coefficient, } \mathrm{W} / \mathrm{m}^{2} \cdot \mathrm{K} \\ T_{w o} & \text { Outside-wall temperature, }{ }^{\circ} \mathrm{C} \\ T_{s} & \text { Saturated temperature, }{ }^{\circ} \mathrm{C} \\ q_{w_{j}} & \text { Local wall heat flux, } \mathrm{W} / \mathrm{m}^{2} \\ \dot{m} & \text { Inner-tube mass flow rate, } \mathrm{kg} / \mathrm{s} \\ H_{j} & \text { Local fluid enthalpy at position } j, \mathrm{~J} / \mathrm{kg} \\ \Delta L_{j} & \text { Distance between two inner-tube temperature } \\ & \text { measure positions } j \text { and } j+1, \mathrm{~m}\end{array}$

Corresponding author: Minghui Duan, engineer, research field: reactor thermo-hydraulics.

$\begin{array}{ll}h_{N B} & \text { Nucleate boiling heat transfer coefficient, } \mathrm{W} / \mathrm{m}^{2} \cdot \mathrm{K} \\ h_{F C} & \text { Convection heat transfer coefficient, } \mathrm{W} / \mathrm{m}^{2} \cdot \mathrm{K} \\ T_{f} & \text { The secondary temperature, }{ }^{\circ} \mathrm{C} \\ \text { Subscript } \\ \text { i } & \text { Inner tube } \\ \text { o } & \text { Outside tube } \\ \text { w } & \text { Wall } \\ \text { j } & \text { Measure position } \\ \text { f } & \text { Fluid }\end{array}$

\section{Introduction}

The PRHR (passive residual heat removal) HX (heat exchanger) is an important emergency core cooling system of AP1000, which can remove the core decay heat by the coolant natural circulation as a result of the different water density. The temperatures between two sides of the PRHR HX tubes differ greatly, and change in a wide range. Many kinds of single-phase and two-phase flow patterns and heat transfer modes are involved. Especially in natural circulation, the flow dynamic characters differ remarkably with the forced circulation because of the 
low flow rate and the great influence by buoyancy. The complex heat transfer characteristics are critical to the performance of PRHR system. Therefore, the HX heat transfer behavior is very important to reactor design and safety assessment.

In America, several tests for PRHR HX in AP600 have been performed to study the heat transfer behavior. The HX was simulated by a test section which consisted of three vertical parallel tubes with no horizontal sections. The heat transfer has been researched between vertical tubes and the cooling tank [1]. However, a PRHR HX tube is in C shape and consists of a middle vertical section, a top horizontal section and a bottom horizontal section. A majority of heat is transferred through the top horizontal section. Besides, the PRHR HX heat transfer area in AP1000 is increased with more HX tubes and longer horizontal sections of tubes. A higher proportion of heat is transferred through the horizontal section in AP1000 than in AP600 [2]. So it's necessary to simulate the natural circulation in C-type HX tubes and research the complicated thermo-hydraulics phenomena in the AP1000 PRHR HX.

In our research, PRHR HX separate-effect tests were performed on a PRHR HX test facility, which consisted of three C-type tubes with typical sizes in AP1000. The experiment purpose was to obtain the natural circulation data, research the HX heat transfer, and develop proper analysis method. The experiment conditions could vary in a wide range covering the operation conditions in AP1000. The test facility could obtain data including the inner-tube water temperatures, the wall surface temperatures along the tubes, the pool water temperatures, the flow rate in tubes and so on. Several tests have been performed for natural circulation in tubes. And the experimental results were compared with the calculations by RELAP5/MOD3.3.

\section{Test Facility}

The PRHR HX test facility was designed to perform heat transfer tests of both natural and forced circulation in HX tubes. The flow path of the test facility was designed in Fig. 1. The main devices of the facility included a PRHR HX test section, a canned pump, a heater, a circulation pump, a heat exchanger in secondary side, a pressurizer, a high water tank, a low water tank, a lift pump, a make-up pump and a spray pump.

There were three C-type tubes in the facility with the same size as the ones in AP1000. According to AP1000, there are $689 \mathrm{HX}$ tubes $(\Phi 19.05 \times 1.65 \mathrm{~mm})$ and the design coolant flow rate is $2.28 \times 10^{5} \mathrm{~kg} / \mathrm{h} \mathrm{[3]}$. So the max design flow rate of three tubes should be $0.276 \mathrm{~kg} / \mathrm{s}$. In our facility, the design flow rate was up to $1.2 \mathrm{~kg} / \mathrm{s}$ which could cover the typical flow rate of the PRHR. By adjusting the motor-driven valves VCO103, VAJ101 and VAJ102 in the primary loop, the system resistance could be controlled, so that the test flow rate could be changed. A mass flow meter was installed in front of the heater to measure the flow rate in the primary loop.

In AP1000, the PRHR HX is operated in $15.5 \mathrm{MPa}$, and the design pressure is $17 \mathrm{MPa}$. The inlet temperature of $\mathrm{HX}$ tubes is $297.2^{\circ} \mathrm{C}$, while the outlet temperature is $92.8^{\circ} \mathrm{C}[3]$. The test facility preserved the full temperature and pressure conditions, and varied over the expected range for AP1000. The inlet water temperature could be adjusted by controlling the heating power of the heater. And the primary pressure was controlled by the pressurizer and the make-up pump.

The PRHR HX test section was the key device of the facility. It consisted of three C-type tubes, a cooling tank and instruments such as thermocouples. The C-type tubes immerged in the cooling tank which simulated the IRWST. When the high temperature water flowed through the tubes, the HX test section transferred the heat from the primary system to the cooling tank by heating and boiling the water in the tank.

The main technical parameters of the test section were shown in Table 1. 


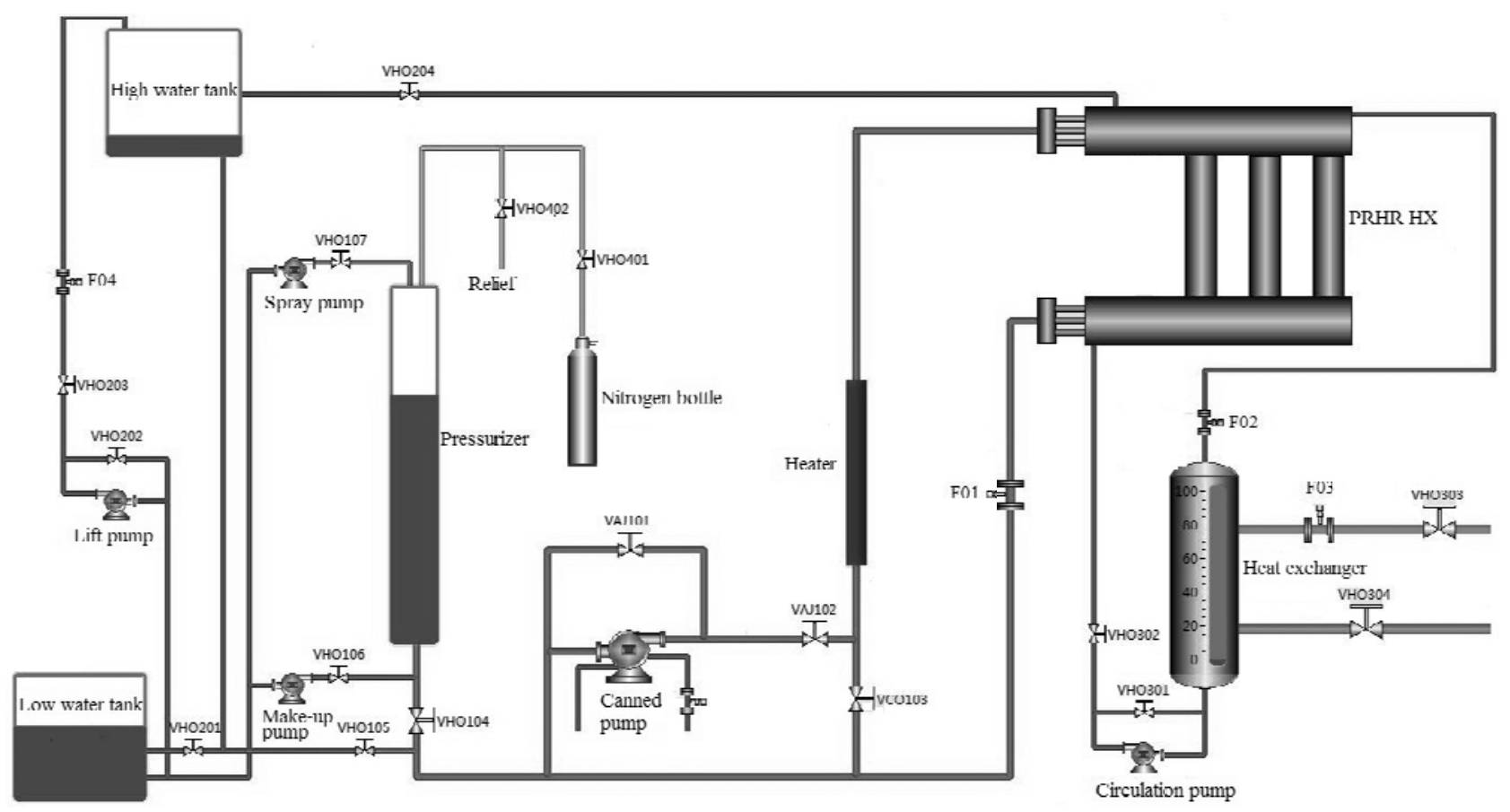

Fig. 1 Flow path chart of the PRHR HX test facility.

Table 1 The main technical parameters of the HX test section.

\begin{tabular}{|c|c|c|c|}
\hline \multicolumn{2}{|c|}{ Test condition } & \multicolumn{2}{|c|}{ Design condition } \\
\hline Tank pressure $(\mathrm{MPa})$ & 0.1 & Tank design pressure $(\mathrm{MPa})$ & 1 \\
\hline Temperature in tank $\left({ }^{\circ} \mathrm{C}\right)$ & $\sim 100$ & Designtemperature in tank $\left({ }^{\circ} \mathrm{C}\right)$ & 100 \\
\hline Tube pressure (MPa) & $\sim 15$ & Tube design pressure (MPa) & 17 \\
\hline Inlet temperature of tubes $\left({ }^{\circ} \mathrm{C}\right)$ & $150 \sim 324$ & Designtemperature in tubes $\left({ }^{\circ} \mathrm{C}\right)$ & 350 \\
\hline Flow rate in each tube $\left(\mathrm{kg} / \mathrm{m}^{2} \cdot \mathrm{s}\right)$ & $200 \sim 2,000$ & Fluid & Deionized water \\
\hline Tank material & 06Cr19Ni10 & Tube material & Inconel 600 \\
\hline
\end{tabular}

Table 2 The tube length.

\begin{tabular}{lll}
\hline Tube No. & Horizontal section length & Vertical section length \\
\hline A (shortest) & $2,586 \mathrm{~mm}$ & $5,284 \mathrm{~mm}$ \\
B (center) & $3,656 \mathrm{~mm}$ & $5,360 \mathrm{~mm}$ \\
C (longest) & $4,724 \mathrm{~mm}$ & $5,436 \mathrm{~mm}$ \\
\hline
\end{tabular}

\subsection{C-Type Tubes}

In the test section, the tube bundle consisted of three C-type tubes. The tubes were in the same vertical plane. Each tube contained a top horizontal section, a bottom horizontal section and a vertical section, which were connected to each other by cutting sleeves. The outer diameter of the test tube was $19.05 \mathrm{~mm}$ and the thickness was $1.65 \mathrm{~mm}$ as the HX tubes in AP1000 [3-5]. The heat transfer for vertical tubes has been researched, so this experiment mainly focused on the heat transfer in horizontal sections. Therefore, the space between horizontal tubes in AP1000 was conserved in the test section. The centerline-to-centerline space between adjacent horizontal tubes was $38 \mathrm{~mm}$. The tube lengths were shown in Table 2 . The tubes respectively simulated the shortest tube, the longest one and the center one of the PRHR HX tubes in AP1000. The material of the tubes was Inconel 600, while that in AP1000 was Inconel 690. There is 6 percent difference in the tube material thermal conductivity. 
The tubes were connected to the primary system pipes by two connectors as shown in Fig. 2. A connector consisted of a vertical cylinder tank and four nozzles as shown in Fig. 3. A top vertical nozzle was used for venting. Three horizontal parallel nozzles were used to connect with the HX tubes respectively. A single horizontal nozzle was used to connect with the primary pipe. The top connector was connected with the outlet line of the heater. The heated water flowed out of the heater and into the test section through the top connector, then out of the test section through the bottom connector. When the high temperature water flowed through the tubes, the C-type tubes transferred the heat from the primary system to the cooling tank by heating and boiling the water in the tank. The inner-tube natural circulation was developed from the density difference between the cold water in the outlet line and the hot water in the inlet line. The top connector was about $10.5 \mathrm{~m}$ above lowest point of the test loop, so the max circulation height was $10.5 \mathrm{~m}$.

\subsection{Cooling Tank}

In America, several tests for PRHR HX in AP600 have been performed. The results indicated that when the space between adjacent tubes was large enough, the thermal effect was independent to each other. Typical P/D (pitch-to-diameter) ration was 1.3 to 1.5 , and in AP600 it was 2 for adjacent tubes. The tests also indicated that when the distance between the tube and the tank wall was large enough, the thermal effect by the tank wall could be ignored [1]. Therefore, in our test facility, the IRWST was predigested to a cylinder tubular tank, as shown in Fig. 2.

The cooling tank consisted of three parallel vertical tubes connected to a top and bottom horizontal tube. Each vertical tube of the tank respectively contained one vertical section of the HX tubes, while the horizontal tube of the tank contained three horizontal sections of the HX tube bundle. The size of the horizontal tubes was $\Phi 325 \times 3.5 \mathrm{~mm}$, and that of the

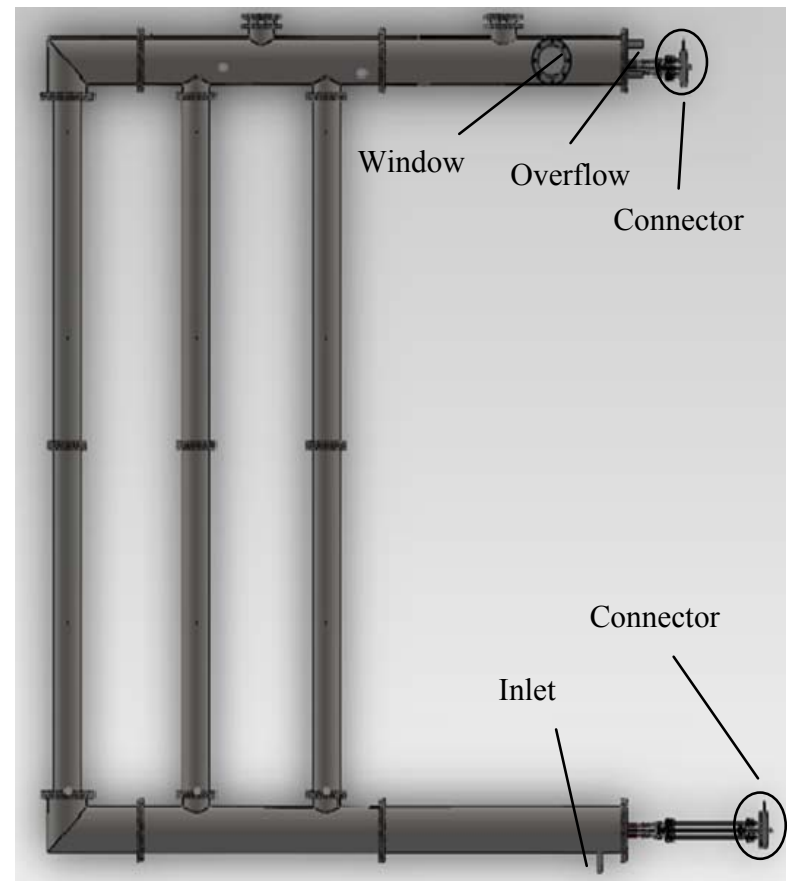

Fig. 2 The cooling tank configuration.

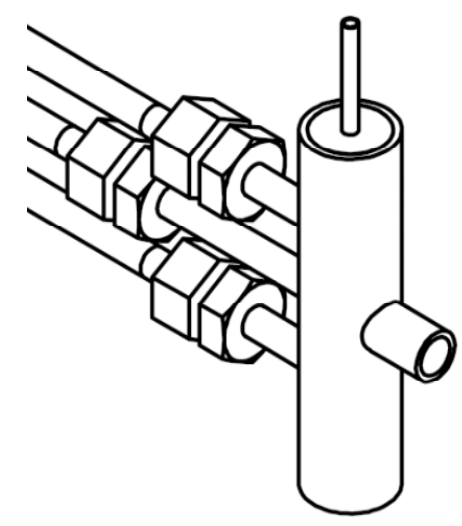

Fig. 3 The connector configuration.

vertical tubes was $\Phi 219 \times 3.5 \mathrm{~mm}$. The distance between the tank wall and the HX tubes was much larger than $38 \mathrm{~mm}$, so the tank size would not affect the heat transfer from the HX tubes to the cooling water, which meant that the predigested cooling tank was feasible.

The secondary cooling water flowed into the cooling tank from the inlet at the bottom, and left it from the outlet on the top flange cover. There was another outlet for the cooling water overflow. In order to observe the heat transfer phenomena in the tank, there were two windows on the tank. 


\subsection{Thermocouples}

In the test section, many temperature data needed to be acquired, including the inner-tube water temperatures, the wall surface temperatures along the tubes and the pool water temperatures.

In order to measure the water temperature in tubes, several thermocouple traps were mounted into the tubes. A thermocouple trap was made of a $\Phi 3 \times 0.5$ $\mathrm{mm}$ seamless stainless steel tube with one end closed and the other open. Several sheathed thermocouples of $0.5 \mathrm{~mm}$ diameter were inserted into the trap from the open end. The thermocouple traps were inserted into and welded to the HX tubes, and supported in the centre of the tubes. By this way, it was assured that the thermocouples measured the centre temperature in the HX tubes. In order to minish the trap influence on the flow in HX tubes, the trap size should be as small as possible. However, there were 10 thermocouples to be installed in A tube, 12 in B tube, 13 in C tube. In order to contain so many thermocouples, the trap size was designed to be $\Phi 3 \times 0.5 \mathrm{~mm}$. Because of the thermocouple traps, the flow cross section in the HX tubes was reduced by $3.6 \%$, which could be accepted.

Several thermocouples were welded on the outer wall surface of the HX tubes to measure the wall surface temperatures. There were 10 thermocouples on A tube, 14 on B tube, 13 on $\mathrm{C}$ tube. Each thermocouple on the wall surface was located between two thermocouples inside the HX tubes.

Besides, 18 thermocouple traps were inserted into and welded to the tank. One thermocouple was installed in each trap to measure the pool water temperatures.

\section{Test Procedures}

Before the natural circulation test started, close valve VAJ101 and VAJ102 to isolate the canned pump from the test loop. Make sure valve VCO103 open. Open valve VHO202 and VHO203, and start the lift pump to pump the water in the low water tank to fill the high water tank. When the high water tank overflowed, shut down the lift pump, and turn off the valve VHO203. Turn on valve VHO105, VHO104 and VHO 204. Because of the gravity, water in the high water tank filled the test loop including the pressurizer, primary pipes and the cooling tank.

When the test loop was full of water, turn off valve VHO105. Feed nitrogen gas into the pressurizer, and start the make-up pump to increase the primary system pressure to the test condition. Then start the heater, which was a vertical pipe connected with the positive pole of DC power at the midpoint and with the negative pole at two ends. When the primary water flowed though the heater, its temperature rose and the density decreased, so the water flowed upwards into the test section. Adjust the heating power to make sure the inlet water temperature of the test section reached the test condition. Adjust the motor-driven valve VCO103 to change the system resistance and control the flow rate in the primary loop. When the hot water flowed through the test section, it was cooled by the cooling tank. The water density increased, so the water flowed downwards and back into the heater. This course formed the natural circulation in the primary loop. Meanwhile, start the circulation pump to circulate the water in the cooling tank through the secondary heat exchanger, and turn on valve VHO303 and VHO304 to cool the tank water.

The natural circulation test in HX tubes was a steady test. When the system was stable, the computer began to record the test data every second including the inner-tube water temperatures, the wall surface temperatures along the tubes, the pool water temperatures, the flow rate in the primary loop, the heating power and so on.

\section{Test Results and Analysis}

The purpose of the PRHR tests was to provide a database to research the heat transfer behavior inside and outside of the PRHR tubes. In our tests, the parameters covered the primary pressure of 2.0-15.5 $\mathrm{MPa}$, the quality in tubes up to 0.2 , the inlet water 
temperature of $150-323{ }^{\circ} \mathrm{C}$, the mass flow rate of $0.15-0.4 \mathrm{~kg} / \mathrm{s}$ and the heating power of up to $364 \mathrm{~kW}$. The test conditions could cover the operation range for PRHR HX in AP1000.

The PRHR HX had several different modes of heat transfer. When the power of the heater was not large enough, water out of the heater could not achieve the saturation temperature. So the heat transfer inside the HX tubes was natural convection. When the power was large enough, the primary water out of the heater was supersaturated. So the heat transfer was nucleate boiling inside tubes. Outside the tubes, the heat transfer was boiling and natural convection in pool. RELAP5/MOD3.3 has been used to model the test facility, simulate the heat transfer inside and outside of the HX tubes and assess the calculation model. There were 3 inner-tube natural circulation test conditions calculated in Table 3.

\subsection{Heat Transfer in the Tube}

The heat transfer was natural convection or condensation in the HX tubes depending on the heating power. In RELAP5, the heat transfer coefficient could be calculated by Dittus-Boelter correlation for single-phase liquid turbulent forced convection [6-8], which is given as:

$$
N u_{D B}=\frac{h_{D B} D_{i}}{k_{i}}=0.023 \operatorname{Re}^{0.8} \operatorname{Pr}^{0.3}
$$

where, $D_{i}$ means the inner-tube diameter, $k_{i}$ means the fluid thermal conductivity, Re means the fluid Reynolds number, Pr means the fluid Prandtl number.

Dittus-Boelter correlation could be applied within the range of parameters: $0.7<\operatorname{Pr}<160, \operatorname{Re}>6,000$, $\frac{L}{D_{i}}>60$ ( $L$ is the tube length $)$.

In our tests, Prandtl number was between 0.8 and
3.2, Reynolds number was above 18,000 , and $\frac{L}{D_{i}}>300$. Though it was natural circulation in tubes, the Reynolds number was very large. Therefore, it was turbulence in tubes, and Dittus-Boelter correlation was chosen in RELAP5 for heat transfer coefficient calculation in these test conditions.

In RELAP5, the heat transfer coefficient could be calculated by the maximum of the Nusselt and Shah correlations for condensation $[6,8]$.

The Nusselt expression is given as:

$$
h_{\text {Nusselt }}=\frac{k_{i}}{\delta}
$$

where, $h_{\text {Nusselt }}$ means the heat transfer coefficient, $\delta$ means film thickness.

The Shah correlation is given as:

$$
h_{\text {Shah }}=h_{s f}\left(1+\frac{3.8}{Z^{0.95}}\right)
$$

where,

$$
Z=\left(\frac{1}{X}-1\right)^{0.8} P_{\text {red }}^{0.4}
$$

and $X$ means static vapor quality, $P_{\text {red }}$ means reduced bulk pressure, $h_{s f}$ means the superficial heat transfer coefficient.

In RELAP5, input the pressure, inlet temperature, the heating power, the mass flow rate and the pool temperature distribution as the boundary conditions, the inner-tube temperature distribution along the tube length could be calculated. The test results and the calculation results of three tubes have been shown in Figs. 4-6.

From all the test results, it can be indicated that the major heat transfer took place at the upper horizontal section of the tubes. Along the tube length, the inner-tube temperature decreased because of the secondary cooling water. Near the inlet, the fluid

Table 3 Test conditions.

\begin{tabular}{llllll}
\hline No. & Pressure $(\mathrm{MPa})$ & Heating power $(\mathrm{kW})$ & $\begin{array}{l}\text { Inlet temperature } \\
\left({ }^{\circ} \mathrm{C}\right)\end{array}$ & Mass flow rate $(\mathrm{kg} / \mathrm{s})$ & Quality $\left(\mathrm{X}_{i}\right)$ \\
\hline FN01 & 15.5 & 364 & 322 & 0.363 & -0.16 \\
FN02 & 8.5 & 228 & 272 & 0.292 & -0.10 \\
FN03 & 6.5 & 203 & 281 & 0.179 & 0.17 \\
\hline
\end{tabular}




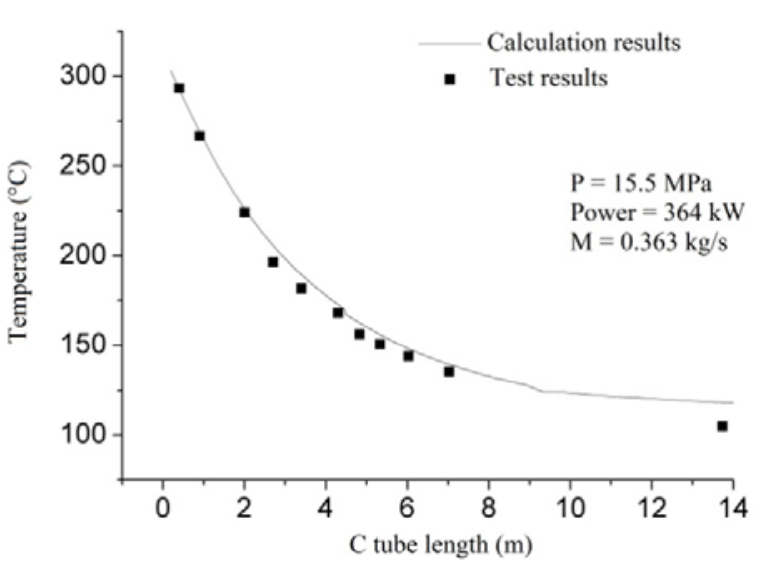

(a)

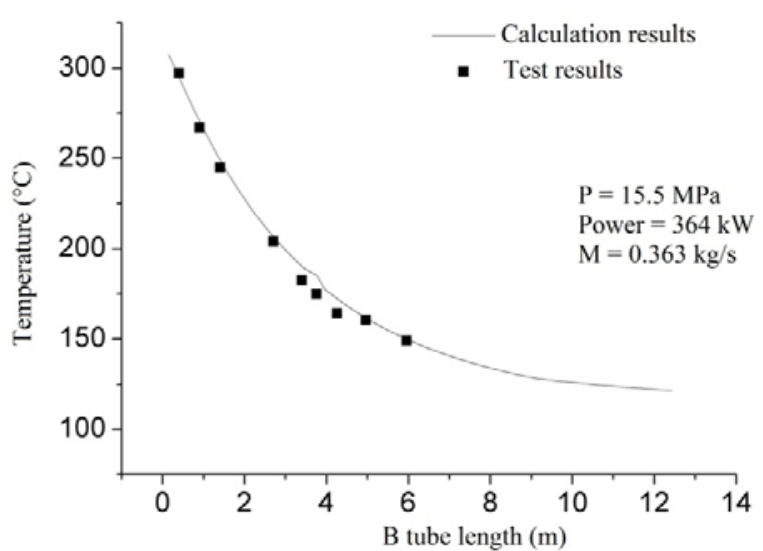

(b)

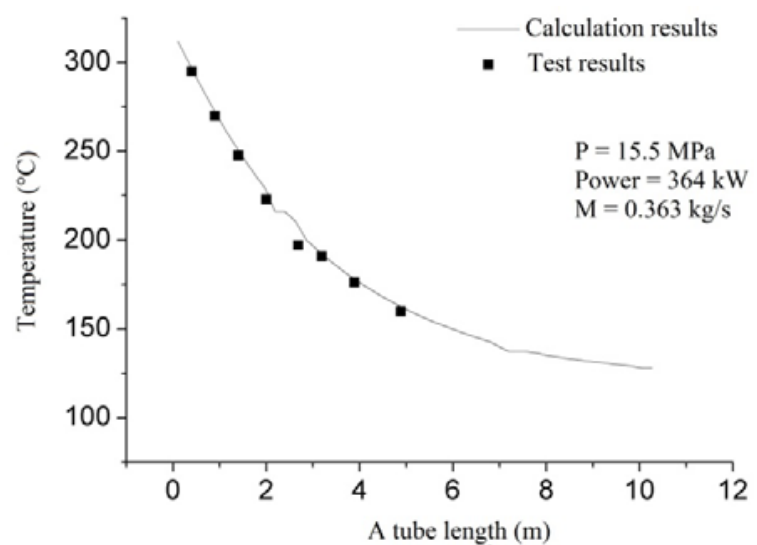

(c)

Fig. 4 The inner-tube temperature comparison of FN01 test.

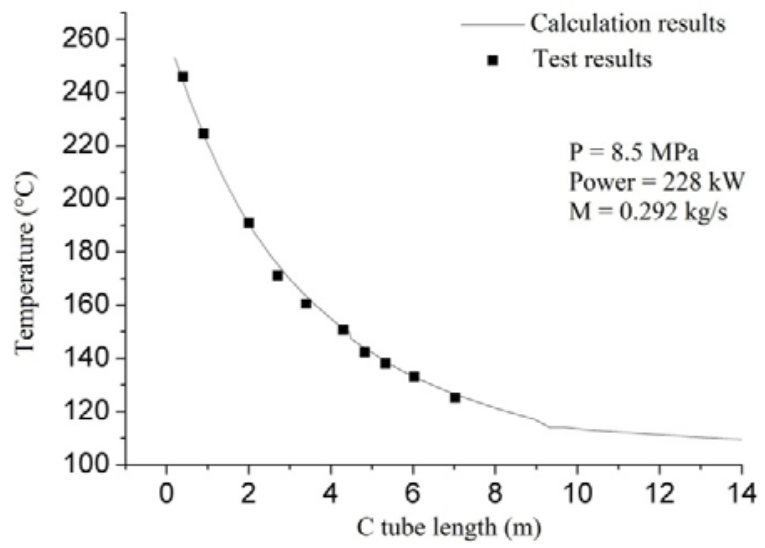

(a)

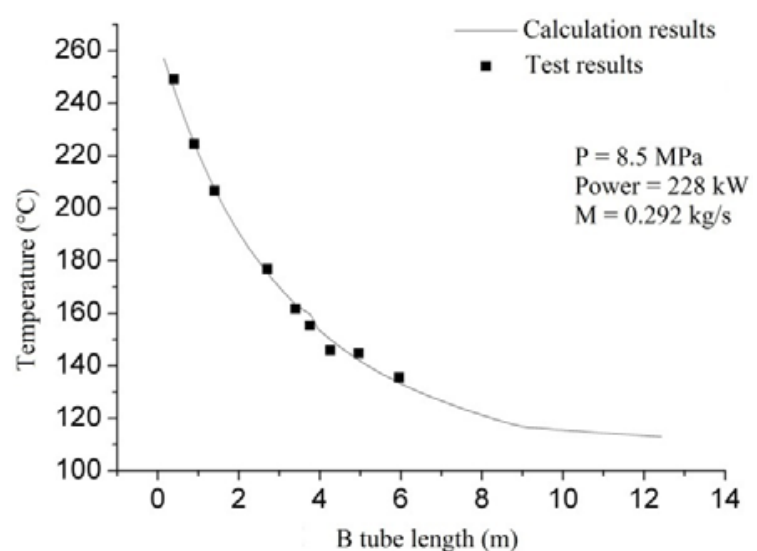

(b)

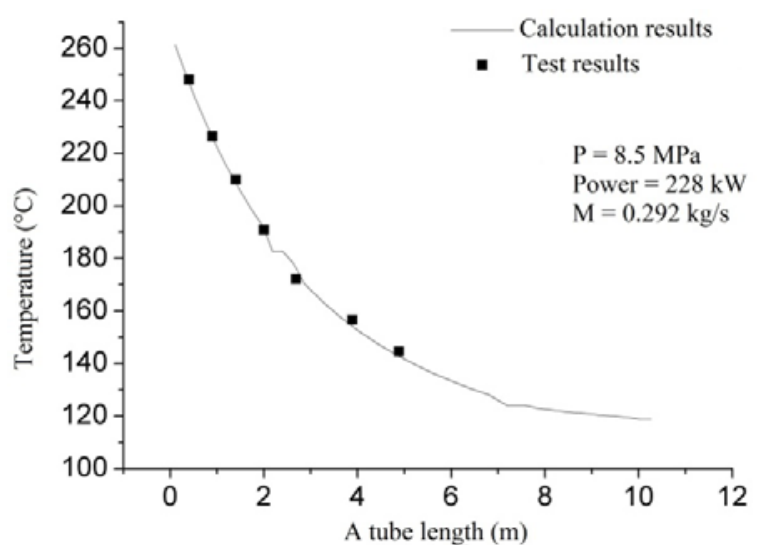

(c)

Fig. 5 The inner-tube temperature comparison of FN02 test. 


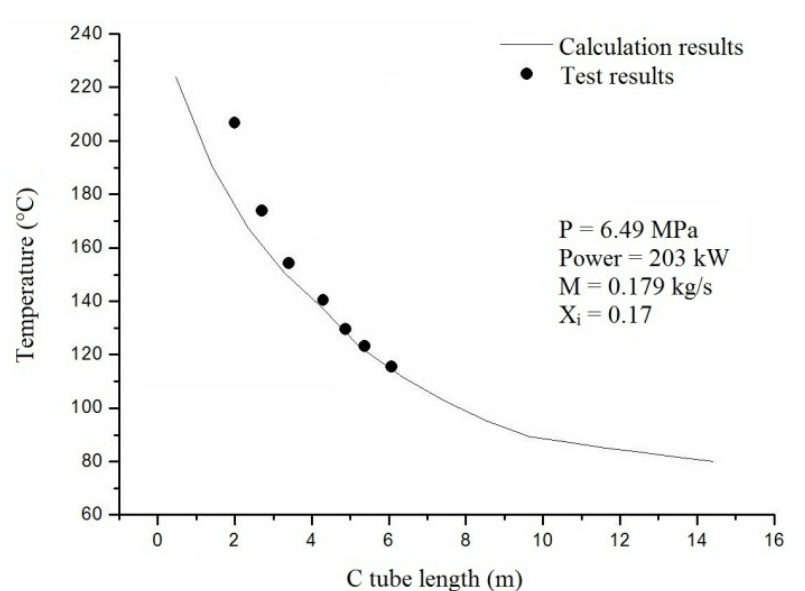

(a)

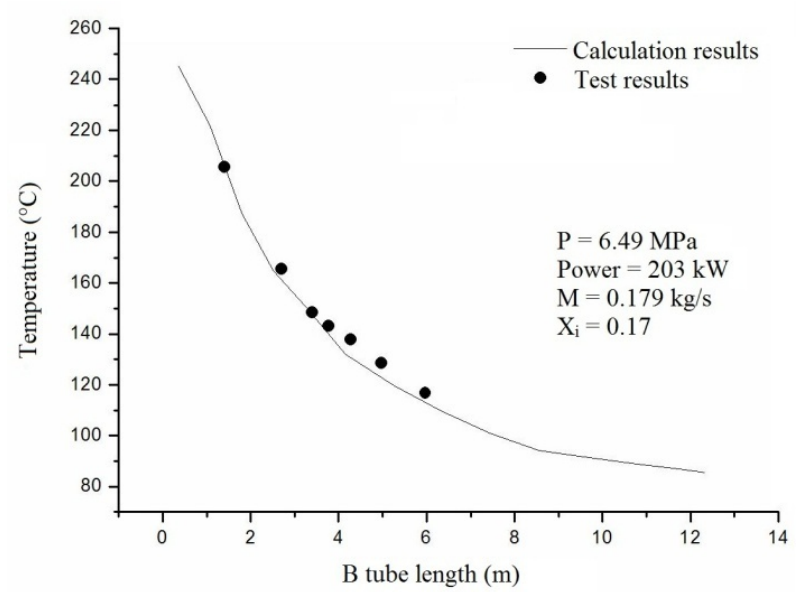

(b)

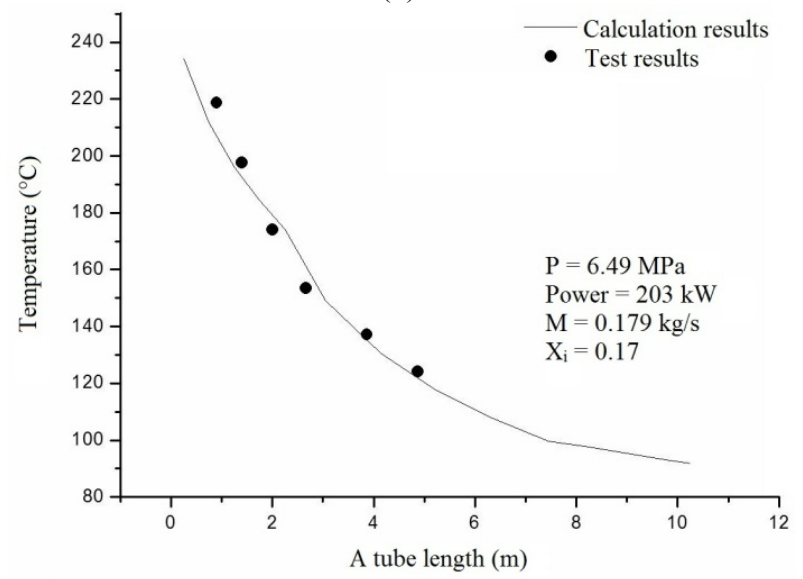

(c)

Fig. 6 The inner-tube temperature comparison of FN03 test.

temperature was high, the heat transfer coefficient and the heat flux were large, so the primary temperature decreased quickly. Along the tube length, the heat flux decreased and the inner-tube temperature dropped gradually slowly.
The test results also indicated that the inner-tube temperature of the upper tube was higher than the bottom one at the same distance from the inlet. That was because in the horizontal section, the temperature of the upper tank water was higher than the bottom, so the heat flux of the upper tube was smaller than the bottom tube.

During the two-phase flow tests, there was two-phase flow instability phenomenon in HX tubes. When the water out of the heater was supersaturated, there was two-phase flow in the HX tubes. The primary system pressure and the natural circulation flow rate fluctuated strongly. That is because in the finite space of the close loop, the quality increase caused the loop pressure rise. With the pressure rise, the water saturation temperature rose, which resulted in the quality and the primary pressure dropped. In order to perform the stable tests, turn down valve VCO103 to increase the system resistance. When the system resistance was large enough, the primary pressure stopped fluctuating and the system became stable. The test results were shown in Fig. 6.

As Figs. 4-6, the comparison between the test data and the calculation results indicated that in both single-phase and two-phase heat transfer conditions, the calculated inner-tube temperatures of three HX tubes agreed well with the test data. Therefore, it can be concluded that Dittus-Boelter, Nusselt and Shah correlations could be applied in RELAP5 to calculate the heat transfer inside the tubes within the test conditions.

\subsection{Heat Transfer in the Cooling Tank}

There were two heat transfer modes outside of the HX tubes: boiling and natural convection, which depended on the tube-wall temperature. Boiling occurred at the horizontal sections of the HX tubes. Near the HX tube inlet, the tubes had sufficient wall superheat $\left(T_{w o}-T_{s}\right)$, so the local nucleate boiling occurred. Along the tube length, the wall temperature dropped because of the secondary cooling water. 
When the wall superheat was not large enough, boiling did not occur. Considering the large volume of the tank, the flow rate in the secondary circulation was very small, so the heat transfer mode could be considered to be natural convection in large room.

The local wall heat flux could be calculated by the steady-state energy balance equation as below:

$$
q_{w_{j}}=\frac{\dot{m}\left(H_{j}-H_{j+1}\right)}{\pi D_{i} \Delta L_{j}}
$$

where, $q_{w_{j}}$ means the local wall heat flux, $\dot{m}$ means the inner-tube mass flow rate, $H_{j}$ means the local fluid enthalpy at position $j$ which was determined by the inner-tube temperature, $\Delta L_{j}$ means the distance between two inner-tube temperature measure positions $j$ and $j+1$.

In RELAP5, the boiling heat transfer coefficient could be calculated by Chen correlation as below.

$$
h_{T P}=h_{N B}+h_{F C}
$$

where, $h_{N B}$ means the nucleate boiling heat transfer coefficient, which is Forster-Zuber pool boiling heat transfer coefficient modified by a suppression factor. $h_{F C}$ means the convection heat transfer coefficient which could be calculated by Dittus-Boelter correlation times a Reynolds number factor.

The boiling heat transfer curve could be correlated by the local wall heat flux and the wall superheat $T_{w o}-T_{s}$ as Fig. 7. The calculation results by RELAP5 were also shown in it. Generally speaking, the calculation trend agreed well with the test data. At low superheat region, the calculated heat flux was close to the test data. At high superheat region, the calculated heat flux was higher than the test data. When the local wall heat flux increased largely, the wall superheat increase slowed down. The wall superheat was less than $30{ }^{\circ} \mathrm{C}$. Compared with the large temperature difference between the inner-tube water and the cooling tank water, the temperature difference in the tank water was relatively small. Therefore, Chen correlation was enough to calculate the boiling heat transfer in the test conditions.

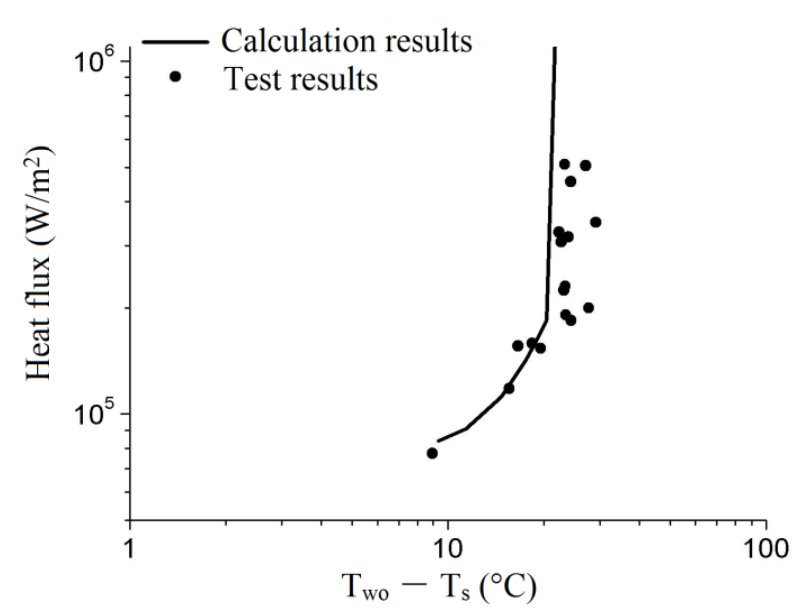

Fig. 7 The boiling heat transfer curve in the cooling tank.

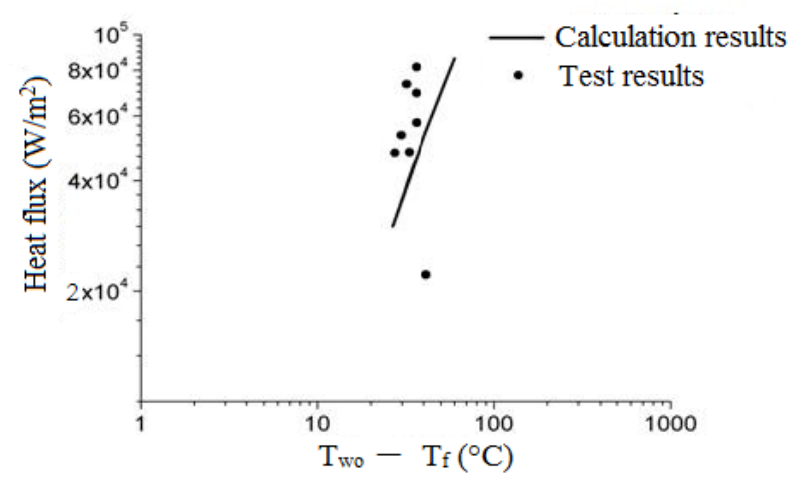

Fig. 8 The natural convection heat transfer curve in the cooling tank.

The natural convection heat transfer coefficient could be calculated by Churchill-Chu and McAdams correlations in RELAP5 [6]. The natural convection heat transfer curve could be correlated by the local wall heat flux and the difference between the wall temperature and the secondary temperature $\left(T_{w o}-T_{f}\right)$ as Fig. 8. The calculation results were also shown in it. The calculated heat flux was lower than the test data, and the calculation trend agreed well with the test data.

Generally speaking, the difference between the inner-tube water and the outside-wall temperature was much larger than that between the tank water and the outside-wall temperature. The main thermal resistance in the PRHR HX existed in the inner-tube natural convection heat transfer and tube wall conductive heat transfer. Therefore, the heat transfer of the primary 
side was more important than the secondary side. For the heat transfer in the cooling tank, RELAP5 could calculate the heat flux with enough accuracy by using Chen, Churchill-Chu and McAdams correlations.

\section{Conclusions}

According to the inner-tube natural circulation experiment research of PRHR HX for AP1000, it can be concluded that: (1) A PRHR HX test facility with 3 typical C-type HX tubes of AP1000 has been built. It can simulate the natural circulation in HX tubes under the pressure of 2.0-15.5 MPa, the quality up to 0.2 , the inlet water temperature of $150-323{ }^{\circ} \mathrm{C}$ and the flow rate of $0.15-0.4 \mathrm{~kg} / \mathrm{s}$, which could cover the operation range in AP1000. (2) The experiment provided lots of important data to research the heat transfer behavior inside and outside of the C-type tubes. (3) RELAP5 could be applied with proper correlations to analyze the heat transfer in PRHR HX under the test conditions.

\section{Acknowledgments}

This research was supported by Large Advanced
PWR Plant National Science and Technology Major Project (2011ZX06004-007-001).

\section{References}

[1] Hochreiter, L. E., Peters, F. E., and Paulsen, D. L. 1997. AP600 Passive Residual Heat Removal Heat Exchanger Test Final Report. WCAP-12980, Revision 3.

[2] Nuclear Regulatory Commission. 2004. Final Safety Evaluation Report Related to Certification of the AP1000 Standard Design. NUREG-1793, Initial Report.

[3] Lin, C. G., and Yu, Z. S. 2008. An Advanced Passive Plant AP1000. Beijing: Atomic Energy Press.

[4] Rryes, J., and Woods, B. 2004. Testing of Passive Safety System Performance for Higher Power Advanced Reactors. US: Oregon State University Press.

[5] Schulz, T. L. 2006. "Westinghouse AP1000 Advanced Passive Plant." Nuclear Engineering and Design 236 (5): 1547-57.

[6] Information Systems Laboratories, Inc. 2001. RELAP5/MOD3.3 Code Manual. Volume IV: Models and Correlation.

[7] Corletti, M. M., Hochreiter, L. E., and Stewart, W. A. 1991. AP600 Passive Residual Heat Removal Heat Exchanger Test. Final Report, WCAP-12980-Rev.0.

[8] Hao, L. M. 2007. Boiling Heat Transfer and Gas (Vapor)-Liquid Two-Phase Flow. Beijing: China National Nuclear Corporation. 